\title{
PSICOLOGIA E RECONHECIMENTO: A CONSTITUIÇÃO DO MUNDO PSÍQUICO E A FORMAÇÃO INTERSUBJETIVA EM WINNICOTT
}

\author{
$\underline{\text { Willima Cintia Santos Barboza }}{ }^{1}$; Carlos César Barros ${ }^{2}$
}

\author{
1. Graduanda em Psicologia, Universidade Estadual de Feira de Santana, e-mail: willima_cintia@hotmail.com \\ 2. Orientador, Departamento de Ciências Humanas e Filosofia, Universidade Estadual de Feira de Santana, e-mail: \\ carlosbarros@uefs.com.br
}

PALAVRAS-CHAVE: Psicanálise; Reconhecimento; Amadurecimento pessoal.

\section{INTRODUÇÃOO}

Fundamentado em uma análise bibliográfica, este trabalho buscou compreender as contribuições da psicanálise das relações objetais para a Teoria do Reconhecimento Social de Axel Honneth. Em "Luta por reconhecimento: a gramática moral dos conflitos sociais", Honneth (2003) realiza uma atualização sistemática das categorias de reconhecimento postuladas por Friedrich Hegel - amor, direito e solidariedade -, lançando mão de teóricos que oferecem fundamentação consistente para o entendimento de tais categorias. Dentro dessa perspectiva, Donald Winnicott contribui para o estudo do amor na mesma linha da perspectiva anti-atomista honnethiana à medida que percebe o desenvolvimento do sujeito como algo vinculado às interações afetivas e sociais.

Baseado na teoria winnicottiana, Honneth desenvolve o conceito de amor a partir da relação que se estabelece entre cuidador/bebê, assim propõe a análise da necessidade do vínculo afetivo para o desenvolvimento do amor de si e da autoconfiança, bem como para o reconhecimento de si e do outro como seres de direitos próprios.

Como objetivou a compreensão da aproximação de Honneth com o pensamento de Winnicott, este trabalho apresentou os seguintes objetivos específicos: identificação dos conceitos psicológicos abordados por Honneth em "Padrões de Reconhecimento Intersubjetivo: amor, direito e solidariedade"; compreensão da relação entre tais conceitos e a teoria winnicottiana; articulação das teorias de Honneth e Winnicott; e a análise da formação do self na perspectiva da psicanálise winnicottiana. Dessa forma, pensando na possível aproximação entre Honneth e Winnicott surgiram alguns questionamentos: qual a relação que pode ser estabelecida entre o cuidado afetivo e a formação intersubjetiva do sujeito? E qual a implicação dessa relação na luta por reconhecimento?

Levando em consideração o desenvolvimento da autonomia e individualidade abordada na teoria do reconhecimento, entende-se que a compreensão da relação que pode ser estabelecida entre Honneth e Winnicott é de fundamental importância para a compreensão da relação entre a formação subjetiva e o reconhecimento dos direitos humanos, portanto, a compreensão das categorias de reconhecimento proporciona o entendimento do processo de construção identitária como resultante das relações estabelecidas com o outro, de modo a estabelecer as bases para a efetivação da luta por reconhecimento.

\section{MATERIAIS E MÉTODOS}

Fundamentada pela discussão sobre padrões de reconhecimento intersubjetivo, efetuada por Honneth (2003) em "Luta por reconhecimento: a gramática moral dos conflitos sociais", cuja análise levou ao entendimento da colaboração da psicanálise das relações objetais de Winnicott para as categorias de reconhecimento, e norteada pela obra "La 
sociedad del desprecio" (HONNETH, 2011), na qual a formação da identidade é apresentada como resultante de um processo de identificação comum entre sujeitos e objetos, esta pesquisa consistiu na compreensão da relação entre os vínculos afetivos e a luta por reconhecimento. Para tanto, foram também utilizadas como referencial bibliográfico as obras "O brincar e a realidade" (WINNICOTT, 1975); "O ambiente e os processos de maturação" (WINNICOTT, 1982) e "Os bebês e suas e mães" (WINNICOTT, 2012).

A investigação bibliográfica foi desenvolvida tendo como base as obras e artigos acadêmicos disponíveis na biblioteca da universidade e no acervo pessoal do orientador e da orientanda. Como se trata de uma pesquisa bibliográfica, o presente trabalho seguiu a metodologia científica desenvolvida por Marconi e Lakatos (2006), com as seguintes etapas de produção: identificação bibliográfica em catálogos de editoras, bibliotecas, bancos de teses e periódicos na internet, análise de resumos e bibliografias das obras encontradas, além da localização, compilação, fichamento, análise e interpretação das obras relevantes para o desenvolvimento do trabalho.

\section{RESULTADOS E DISCUSSÃO}

Dentro da perspectiva honnethiana, a teoria do amadurecimento pessoal de Winnicott remete à compreensão da forma mais primitiva de reconhecimento - o cuidado afetivo, que se estabelece inicialmente na relação amorosa entre cuidador e bebê, uma vez que esta enfatiza a formação do eu (self) como derivada das relações afetivas desenvolvidas entre os sujeitos e os objetos externos. No processo de amadurecimento, a formação do sujeito e o desenvolvimento de sua autonomia estão diretamente relacionados à ruptura gradual entre o sujeito e objeto, bem como às experiências de cuidado e dedicação iniciadas em estágios primitivos do desenvolvimento.

Sendo assim, a constituição do sujeito dá-se progressivamente a partir da relação entre cuidador e bebê, a qual proporciona a continuidade do processo de amadurecimento, possibilitando a formação do self e a integração psicossomática. Portanto, a existência do sujeito enquanto uma unidade integrada e independente depende das interações com o ambiente e de uma comunicação sutil e silenciosa que mantém a vivacidade da relação mãe-bebê.

Dentro desse processo, o desenvolvimento da criança torna-se possível através da criação de um espaço potencial entre a realidade e a fantasia. Por meio dessa área intermediária, proporcionada pela mãe, a criança imagina, cria e reconhece a realidade externa e os objetos do ambiente como 'não-eu', assim dá início ao seu relacionamento com o mundo, o qual é inicialmente proporcionado pelo uso dos objetos transicionais, e posteriormente pelo brincar e a experiência cultural. Desse modo, o brincar configura-se como um modo de estruturação da realidade simbólica e da criatividade, pois oferece à criança a possibilidade de sustentar uma realidade interna que está em constante mudança. Assim, a brincadeira representa um espaço criativo e potencial para vir-a-ser, possibilitando o reconhecimento da criança dentro do contexto social e familiar no qual está inserida, possibilitando também a dissociação da relação entre cuidador e criança, uma vez que gradualmente se reconhecem como sujeitos independentes e autônomos, dando início à ruptura do estado de indiferenciação.

Em função da percepção da realidade externa a criança desenvolve além dos fenômenos de transicionalidade uma tendência para a realização de atos agressivos. Durante o processo de desenvolvimento, a criança coloca à prova o amor do outro, submetendo a mãe a uma série de atos agressivos. A partir da sobrevivência materna de forma afetuosa e acolhedora, o bebê torna-se capaz de amá-la mesmo que a reconheça como um ser independente. Assim, esses indivíduos encontram-se dependentes do amor 
recíproco do outro. Portanto, a agressividade infantil representa a base para "o reconhecimento do objeto como entidade por seu próprio direito" (WINNICOTT, 1975, p. 125).

Levando em consideração a teoria winnicottiana, Honneth (2003) destaca que o desenvolvimento das relações afetivas é derivado da experiência simbiótica e da relação do bebê com os objetos subjetivos. Dessa forma, a constituição do eu está atrelada às interações estabelecidas dentro do contexto social, sendo o cuidado afetivo entre a mãe e o bebê a forma de reconhecimento mais primitiva. Nesse sentido, a agressividade e as tentativas inconscientes de destruição representam uma luta por reconhecimento, à medida que encontram reciprocidade na continuidade do amor do outro.

Dessa forma, a relação que a criança estabelece com os objetos externos e o ambiente conduz ao estabelecimento da autoconfiança, que proporciona $\mathrm{o}$ desenvolvimento da capacidade de estar só. De acordo com Winnicott (1958/1983), tal capacidade surge da experiência de ficar só na presença do cuidador. Assim, o amor como forma de reconhecimento, descrito por Hegel como 'ser-si-mesmo no outro', requer a existência de interações comunicativas, de modo que o sujeito consiga fazer uso do ambiente real e compartilhado e ao mesmo tempo entenda a sua dependência com relação ao outro, proporcionando um "recíproco estar-consigo-mesmo no outro" (HONNETH, 2003, p. 175). Em suma, o desenvolvimento dessa forma de reconhecimento possibilita a compreensão de si e do outro como sujeitos sociais e parceiros de interação. Sendo assim, o cuidado afetivo é a base para a formação de uma identidade pessoal e coletiva, bem como para o estabelecimento das relações com outros sujeitos. Portanto, a partir do amor são constituídas as bases afetivas e motivacionais para a reivindicação dos direitos tanto individuais quanto coletivos.

\section{CONSIDERAÇÕES FINAIS}

A partir da atualização do conceito de reconhecimento, Honneth destaca que a capacidade de vinculação dos sujeitos, através de uma perspectiva intersubjetiva, requer o desenvolvimento da autoconfiança e da percepção da continuidade do amor e dedicação do outro. Dentro dessa perspectiva, a reivindicação e o reconhecimento dos direitos e deveres dentro de uma dimensão social dependem necessariamente do estabelecimento de uma relação afetiva e cuidadosa nos primeiros estágios do desenvolvimento.

As relações afetivas primárias constituem a base para as outras esferas de reconhecimento recíproco. Partindo da experiência intersubjetiva de amor para as demais categorias de reconhecimento, o sujeito encontra na união dessas esferas o reconhecimento necessário para a luta por direitos. Portanto, essa esfera primitiva de reconhecimento, juntamente com o direito e a solidariedade, é responsável pela constituição moral e subjetiva dos sujeitos, uma vez que representa o pressuposto psíquico para o desenvolvimento de outras atitudes de autorrespeito (HONNETH, 2003).

Sendo assim, a compreensão de um estado de dependência proporcionada pela teoria winnicottiana evidencia a possibilidade de amadurecimento e formação do self através da perspectiva intersubjetiva, uma vez que a possibilidade de existência dos sujeitos encontra-se, essencialmente, no seu relacionamento com o outro. Dentro dessa perspectiva, a possibilidade de aproximação entre os autores torna-se possível à medida que ambos destacam a necessidade de relacionamento com o outro dentro do processo de desenvolvimento, dessa forma, o reconhecimento da necessidade de relacionamento com os parceiros de interação oferece suporte para a luta por reconhecimento. 


\section{REFERÊNCIAS BIBLIOGRÁFICAS}

HONNETH, A. La sociedad del desprecio. Madri: Trotta, 2011.

Luta por reconhecimento: a gramática moral dos conflitos sociais. São Paulo: Ed. 34, 2003.

MARCONI, M.A.; LAKATOS, E.M. Metodologia do trabalho científico: procedimentos básicos, pesquisa bibliográfica, projeto e relatório, publicações e trabalhos científicos. 6 ${ }^{\mathrm{a}}$. Ed. São Paulo: Atlas, 2006.

WINNICOTT, D. W. A capacidade de estar só (1958). In: O ambiente e os processos de maturação: estudos sobre a teoria do desenvolvimento emocional. Porto Alegre: Artes Médicas, 1983, p. 31-37.

A preocupação materna primária (1956). In: Da pediatria à psicanálise: obras escolhidas. $2^{\text {a }}$ ed. Rio de Janeiro: Imago, 2000, p. 399-405.

A mente e sua relação com o psicossoma (1949). In: Da pediatria à psicanálise: obras escolhidas. $2^{\text {a }}$ ed. Rio de Janeiro: Imago, 2000, p. 332-346.

O brincar e a realidade. Rio de Janeiro: Imago, 1975.

2012.

Os bebês e suas mães. $4^{\mathrm{a}}$ ed. São Paulo: Editora WMF Martins Fontes, Sobre as bases para o self no corpo (1970). In: Explorações psicanalíticas. Porto Alegre: Artmed, 2005, p. 203-218. 